\title{
A QUALIFICAÇÃO PROFISSIONAL DOS EGRESSOS DO INSTITUTO FEDERAL DE EDUCAÇÃO, CIÊNCIA E TECNOLOGIA DO CEARÁ - IFCE
}

\author{
K. S. L. CRUZ ${ }^{*}$, A. A. SOUSA E I. M. S. P.CARNEIRO \\ Instituto Federal de Educação, Ciência e Tecnologia do Ceará - IFCE \\ socialkeyla@yahoo.com.br*
}

Artigo submetido em outubro/2013 e aceito em dezembro/2013

DOI: $10.15628 /$ rbept.2013.3552

\section{RESUMO}

As transformações contemporâneas no mundo do trabalho implicam na aquisição de novas habilidades e competências que transcendem as possibilidades do sistema educacional, sendo exigido um novo perfil de trabalhador. Tendo em vista essas considerações, esta pesquisa visa analisar a qualificação profissional viabilizada pelo IFCE, a partir da ótica dos Egressos que se formaram no período de 2007.1 - 2013.2. Esta pesquisa, de natureza quanti-qualitativa, teve como amostra 68 egressos, representando $20 \%$ do universo. Utilizou-se o questionário on line para a coleta dos dados, tendo como referencial teórico autores como Paiva (2000) e Ramos (2002). Dentre os resultados, destacamos que $75 \%$ dos egressos, informaram que o curso contribuiu para sua inserção no mercado de trabalho. Contudo, ressaltam a necessidade de obtenção de conhecimentos e habilidades que mais se aproximem da realidade prática. Finalmente, 94\% dos egressos retornariam à Instituição para dar prosseguimento aos seus estudos. É válido ressaltar que esses resultados não podem estar desvinculados da própria dinâmica da Sociedade Capitalista que se apropria ideologicamente da ideia do Capital Humano, adequando à educação às demandas do mercado de trabalho, marcado pela flexibilização das relações de produção e precarização das condições de trabalho.

PALAVRAS-CHAVE: Qualificação Profissional; Formação Integral; Egressos.

\section{THE PROFESSIONAL QUALIFICATION OF GRADUATES FROM INSTITUTO FEDERAL DE EDUCAÇÃO, CIÊNCIA E TECNOLOGIA DO CEARÁ - IFCE}

\begin{abstract}
Contemporary changes into the labor world involve the acquisition of new skills and competencies that transcend the possibilities of educational system, requiring a new profile for workers. Therefore, this research aims to analyze the qualification enabled by IFCE, considering the perspective of graduates who graduated during 2007.1 2013.2. This research, based on quantitative and qualitative data, sampled 68 graduates, representing $20 \%$ of the whole. We used an online questionnaire for data collection, supported by theoretical framework authors such as Paiva (2000) and Ramos (2002). Among the results, we point out that $75 \%$ of graduates reported that
\end{abstract}

the course contributed to their integration into the labor market. However, they also highlight the need of gaining knowledge and skills that could be closer of their day-byday reality. All in all, $94 \%$ of graduates would return to the institution to proceed with their studies. It is worth noting that these results cannot be disconnected from the dynamics of Capitalist Society that, ideologically, uses the idea of human capital in order to adapt education to the demands of the labor market, characterized by the easing of relations of production and by precarious working conditions.

KEYWORDS: Professional Education; Integral Training; Graduates. 


\section{INTRODUÇÃO}

As transformações contemporâneas no mundo do trabalho, vinculadas à generalização da microinformática e às novas formas de comunicação e mudanças organizacionais e gerenciais, implicam na aquisição de novas habilidades e competências. Estes atributos transcendem as possibilidades do sistema educacional, sendo exigido um novo perfil de trabalhador, com capacidade de vencer as dificuldades através de iniciativas pessoais e do desenvolvimento de atividades alternativas, de modo a se adequar às exigências do atual sistema de produção flexível.

Essas tendências acarretam num processo de reordenamento da educação profissional brasileira, cabendo, muitas vezes, às instituições escolares o papel de garantir uma "formação" adaptável aos ditames do processo de globalização e à crise do emprego. Nesse contexto, a qualificação profissional é resignificada pela formação pautada no modelo de Competências ${ }^{1}$, visando garantir condições de empregabilidade ao trabalhador.

Diante desse cenário, os Institutos Federais de Educação Profissional e Tecnológica - IF's têm adquirido importante responsabilidade na formação dos trabalhadores, principalmente, por fornecerem a base teórica e metodológica para o egresso atuar no mundo do trabalho. Assim, pesquisas com egressos se fazem importantes, por contribuírem com informações na perspectiva de avaliação dos cursos, apontando caminhos na possibilidade de garantir uma formação integral, não restrita aos aspectos técnicos e operacionais, mas que envolva conhecimentos de natureza política, cultural, econômica e social.

Tendo em vista estas considerações, o presente trabalho visa analisar a qualificação profissional viabilizada pelo Instituto Federal de Educação Profissional e Tecnológica do Ceará IFCE, Campus Maracanaú ${ }^{2}$, a partir da ótica dos Egressos que concluíram os cursos técnicos e superiores no período de 2007.1 - 2013.2. O Campus oferece cursos técnicos em Automação Industrial, Informática, Meio Ambiente e Redes de Computadores; além de cursos superiores: Bacharelado em Ciências da Computação e em Engenharia Ambiental e Sanitária, Licenciatura em Química e Tecnologia em Manutenção Industrial.

A pesquisa ancorou-se na metodologia qualitativa e quantitativa, apresentando abordagem descritiva e com utilização do questionário, dotado de perguntas fechadas e abertas, disponível através do meio eletrônico. A população do estudo se constituiu de um universo de 329 egressos, que concluíram cursos superiores e técnicos (supramencionados) no período 2007.1 a 2013.2, dos quais foi estabelecido contato com 68 , representando $20 \%$ do total, número que se constituiu de amostra.

Ressaltamos que esta pesquisa se configura como um recorte de um mapeamento realizado em junho de 2014, cuja densidade de informações ${ }^{3}$ nos levou a apresentar, neste

\footnotetext{
${ }^{1}$ Esse conceito tem sua origem no âmbito empresarial (Hirata, 1994), correspondendo a um modelo pós-taylorista de qualificação. A Formação pelo modelo de competências valoriza aspectos pessoais e disposições subjetivas, englobando não somente aspectos técnicos, mas também a socialização.

2 O IFCE- Campus Maracanaú está localizado no município de Maracanaú. Este município está localizado na Região Metropolitana de Fortaleza, situando-se a $13 \mathrm{~km}$ da capital cearense. O município fazia parte de Maranguape, mas, a partir do ano de 1975, passou a sediar o Distrito Industrial de Fortaleza, sendo emancipado de Maranguape em 1983. ${ }^{3} \mathrm{O}$ questionário levantou as seguintes informações: o perfil básico dos participantes desta pesquisa, partindo de informações a respeito do sexo, idade, município em que está residindo atualmente e estado civil. No segundo Momento, realizamos um levantamento detalhado do perfil acadêmico e profissional do Egresso, tomando como
} 
trabalho, informações a respeito das expectativas dos egressos sobre a formação adquirida; as demandas do mercado de trabalho, bem como a respeito do interesse do egresso em retornar à Instituição para dar prosseguimento a seus estudos. Ademais, este mapeamento teve o propósito de subsidiar investigações posteriores nesta área, além de fornecer informações aos gestores acerca da condição atual dos egressos, no período mencionado. Esta ação é relevante, sobretudo, neste momento, em que a referida instituição amplia a sua atuação para várias localidades do Estado, aumentando assim, sua responsabilidade social. As informações podem ser utilizadas, ainda, pelos profissionais formados na área, jovens que estão definindo sua carreira profissional, e instituições que integram o sistema público de formação profissional.

\section{QUALIFICAÇÃO PROFISSIONAL E/OU FORMAÇÃO PELO MODELO DE COMPETÊNCIAS: DISCUSSÃO SOBRE AS TENDÊNCIAS ATUAIS}

As discussões teóricas em torno da Qualificação Profissional e da Formação pelo modelo de Competências serão desenvolvidas ao longo desse tópico tomando como referência Paiva (1999) e Ramos (2000), uma vez que subsidiarão a análise dos dados empíricos da pesquisa em tela.

Segundo Paiva (1999), novos requisitos de qualificação são demandados aos trabalhadores frente à intensificação do debate sobre a reestruturação produtiva industrial. A discussão central em torno da adequação da força de trabalho a essa reestruturação, a partir dos anos de 1990, sofre um deslocamento frente à retração do mercado de trabalho (excludente e fragmentado) e ao deslocamento do foco econômico-social para atividades fora do setor da indústria.

A centralidade dessas discussões passou a ser direcionadas para a busca de uma qualificação não restrita aos conhecimentos formais, mas à aquisição de habilidades e conhecimentos que se adequassem às novas demandas profissionais: capacidade de abstração, de concentração e exatidão. Estas capacidades não são requisitos viabilizados somente pela educação geral, mas envolve conhecimentos psicológicos da formação.

Sendo assim, assistimos a um duplo processo em que, de um lado, verificamos elevação das taxas de emprego e novas condições de trabalho precarizado, com desregulamentação dos direitos trabalhistas; e, por outro lado, o reordenamento social das profissões, marcado pela elevação da qualificação ao mesmo tempo em que os salários decrescem e o status profissional pautado na carreira, construída em longo prazo, se enfraquece.

Nesse contexto, alguns estudiosos (KERN E SCHUMANN, 1984; PAIVA, 1999) apontam para o fim tendencial da divisão do trabalho, na medida em que o trabalho intelectual acopla-se de forma cada vez mais visível com o trabalho manual (CHINELLI e DURÃO, 1999). Isso significa

\footnotetext{
base de análise informações a respeito do curso realizado, nível de habilitação, tempo de conclusão dos estudos no Campus, detalhamento das atividades que atualmente está realizando seja remunerada ou não, e se tal atividade se dá nas áreas de formação, além da identificação do espaço ocupacional atual e da faixa de remuneração. Finalmente, buscamos delinear a Política de Atendimento aos egressos, por meio de informações a respeito das expectativas do mesmo sobre a formação adquirida e as demandas do mercado de trabalho, bem como a respeito do interesse do egresso em retornar à Instituição para dar prosseguimento a seus estudos.
} 
novas exigências direcionadas para o conhecimento de novos conteúdos de trabalho, pautados na produção e gestão de comunicações e controle dos sistemas de informação. Essas tendências requerem um profissional que domine estes novos conteúdos, implicando na manipulação de signos, símbolos e códigos.

Desta forma, vislumbramos a necessidade de qualificações e competências que transcendem as possibilidades do sistema educacional: não basta conhecimento, mas interesse, motivação e criatividade. A qualificação não se restringe ao trabalho, mas é uma aquisição para a vida toda, nesse sentido, novas exigências são postas a educação, com ênfase na formação continuada do trabalhador.

Reconhecemos que as tendências em curso vivenciadas na atualidade contribuem para o enfraquecimento do conceito de qualificação pela competência. Isso traz implicações no âmbito econômico, social e educacional, quais sejam: desfiliação dos trabalhadores do sistema de regulações sociais, dada as condições de precarização do trabalho e flexibilidade do processo de acumulação capitalista; e redução da educação profissional a formações restritas ao mercado de trabalho.

Na opinião de Paiva (2000), enquanto a qualificação está vinculada às instituições formais e as experiências adquiridas, a competência valoriza aspectos pessoais e disposições subjetivas, englobando não somente aspectos técnicos, mas também a socialização. É importante frisar que a autora não considera que a competência tenha um sentido mais restrito que a qualificação, mas que aquela atende de forma mais adequada às necessidades do capital, estando vinculada a noção de empregabilidade 4 . Contudo para Ramos (2000) ocorre um processo de redimensionamento da qualificação pela formação pautada no modelo de competências, sendo esta uma importante ferramenta com a utilidade de reforçar a subsunção da Educação aos ditames do Capital.

A formação pautada no modelo de competências é vislumbrada por Ramos (2002) sob dois vieses: a) reordenar conceitualmente a compreensão da relação trabalho/educação, visando desviar a atenção da problemática dos empregos, das ocupações e das tarefas, no que diz respeito às suas implicações na subjetividade do trabalhador; b) institucionalizar novas formas de educar/formar os trabalhadores e gerir internamente às organizações e no mercado de trabalho em geral, sob novos códigos profissionais.

Diante desse cenário, Ramos (2002) defende o conceito de qualificação enquanto dimensão social, pois permite estabelecer uma relação dialética entre os saberes e a configuração da divisão social e técnica do trabalho. Em outras palavras, reconhece que a qualificação está inserida numa dinâmica social, síntese das dimensões conceitual, experimental e social.

Defendemos que conceito de Qualificação profissional não pode se restringir ao acumulo de conhecimentos teóricos ou de natureza técnica e/ou operacional, pensadas de forma estanque, mas engloba uma formação humanística, artística, cultural e política. Nesse sentido, a instituição escolar, apesar de suas limitações, ainda é um importante espaço de formação, apesar da

\footnotetext{
${ }^{4} \mathrm{O}$ conceito de empregabilidade não é atual, mas ganha força entrando nas discussões acadêmicas e políticas brasileiras a partir dos anos de 1990. A empregabilidade diz respeito à qualificação, às habilidades, disposição, atitudes do indivíduo frente a um mercado de trabalho que não está em expansão. Transfere-se do social para o individual a responsabilidade pela inserção profissional dos indivíduos. (PAIVA, 2000).
} 
existência de contradições no processo formativo. Se por um lado, a escola reforça uma formação tecnicista, está garantindo o processo de exploração da força de trabalho, visando à acumulação de mais valia pelo Sistema Capitalista. Mas, se por outro, garanti uma formação autônoma e política, voltada também para a classe trabalhadora, com certeza contribuirá para a elaboração e consolidação de um projeto societário e político de contestação do sistema vigente.

\section{RESULTADOS DA PESQUISA}

Analisando os dados do Gráfico 1, verificamos que um número considerável, representado por 51 egressos, correspondendo a 75\% da amostra, informou que o curso que finalizou no IFCE, Campus Maracanaú contribuiu para sua inserção no mundo do trabalho. Inclusive, para um dos egressos do Curso Técnico em Desenvolvimento de Software, foi mais importante, para obtenção de trabalho, concluir o Curso Técnico do que o Superior que, atualmente, está cursando em uma Instituição de Ensino Superior (IES) particular.

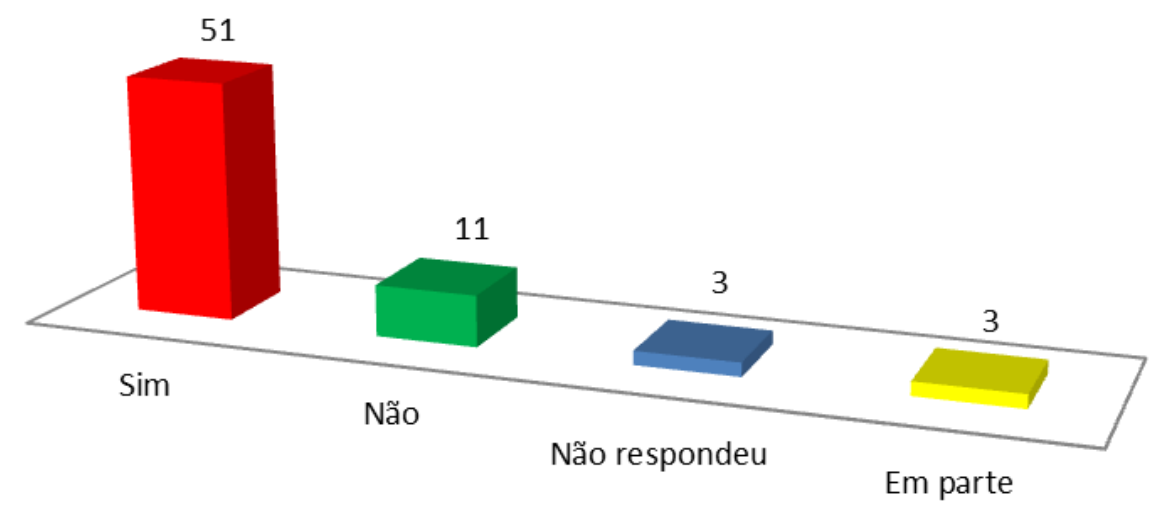

Gráfico 1: Perspectiva do Egresso sobre a qualificação adquirida e sua relação com as demandas do trabalho Fonte: Pesquisa Direta, 2014

Dentre as motivações que favoreceu essa correlação positiva, entre a formação adquirida e as demandas profissionais, destacamos as seguintes justificativas:

1) Garantia de boa base de conhecimento do curso finalizado, propiciando um bom desempenho profissional;

2) Relação da Formação adquirida com a prática profissional (através dos laboratórios), garantindo experiência de trabalho, requisito bastante valorizado pelo mercado de trabalho;

3) A formação teórica adquirida vem relacionada com uma infraestrutura e recursos humanos de qualidade, garantindo resultados positivos;

4) Alguns cursos técnicos como Automação Industrial são bastante demandados pelo mercado de trabalho, acarretando em mais procura do que oferta de profissionais para atuarem nesta área.

5) A maioria dos Cursos do IFCE- campus Maracanaú oferece uma ótima formação teórica, apesar da constante necessidade de atualização e aquisição de conhecimentos diante das demandas do mercado de trabalho. 
Dando continuidade na análise dos dados, um quantitativo de 3 egressos ( 2 advindo dos Cursos do Eixo da Telemática e 1 do Curso Superior em Manutenção Industrial), representando 4\% da amostra, afirmaram que, em parte, o curso atende as demandas do mundo do trabalho, existindo alguns aspectos que devem ser levados em consideração tais como:

1) A necessidade de que deveria ter estudado "mais coisas", porém o nível da turma não permitiu isso (Egresso do Curso Técnico em Desenvolvimento de Software);

2) A existência de algumas deficiências, como por exemplo a falta de um pouco mais de prática (Egresso do Curso de Desenvolvimento de Software);

3) Exigência do mercado de trabalho pelo técnico em Automação ao invés do tecnólogo, provocando desestímulo do egresso pelo Curso. Na opinião de um dos Egressos advindo do Curso Superior em Manutenção industrial: "o IFCE é o único órgão que abre concurso para tecnólogo, mas o mercado não tem abertura para esses profissionais, apenas para o técnico".

Apesar da maioria dos egressos opinarem de forma positiva sobre a relação da formação adquirida com as demandas profissionais, um quantitativo de 11 egressos, correspondendo a 16\%, informaram que, diante da complexidade do mundo do trabalho, fica difícil acompanhar as novas exigências postas, sendo necessário "um profissional atualizado".

Diante de um mercado de trabalho exigente por trabalhadores melhores qualificados, consideramos que é disseminada a ideia da necessidade de busca do indivíduo por capacitação constante, visando propiciar condições mais favoráveis para a "empregabilidade", mas não garantindo a obtenção de bons salários, muito menos o emprego.

As falas dos sujeitos a seguir ilustram o tipo de qualificação que na perspectiva do egresso deve ser adquirida para possibilitar maiores perspectivas de obtenção de trabalho.

A base da formação é boa, mas o mercado se atualiza muito rápido, sendo assim deveríamos ter cursos de extensão em ferramentas utilizadas no mercado junto a um incentivo financeiro para que o aluno possa se manter no curso (Egresso $n=13$ - Curso técnico em Informática);

Não, pois o que vimos no curso foi apenas conhecimentos teóricos a respeito da área de automação industrial, e como estou trabalhando na área vi que precisa muito deste diferencial (Egresso no 10 -Curso Técnico em automação industrial).

A compreensão dos sujeitos obtidas no questionário demonstram as lacunas na formação, devido à desarticulação entre a teoria e a prática, sendo necessária a obtenção de conhecimentos e habilidades que mais se aproximem da realidade prática. Nesse sentido, o conceito de qualificação vai sendo redimensionado para uma formação pautada na competência que valoriza aspectos pessoais e disposições subjetivas.

Com efeito, a noção de competência traz consigo outra mentalidade em relação ao trabalho, sendo necessária a aquisição de conhecimentos e habilidades no uso das tecnologias (alfabetização tecnológica), naturalização da fragmentação, precarização e intensificação do trabalho. O risco e a incerteza passam a serem elementos constituintes explícitos do mundo do trabalho (PAIVA, 1999). 
Válido ressaltar que as falas dos egressos pesquisados devem ser contextualizadas, levando em consideração a própria dinâmica da Sociedade Capitalista que se apropria ideologicamente da ideia do Capital Humano ${ }^{5}$, de modo a garantir a apropriação de competências e habilidades adequadas à nova realidade, marcada pela flexibilização das relações de produção e reprodução da riqueza do Sistema e precarização das condições de trabalho.

No Gráfico 2 é possível observar a perspectiva do egresso quanto ao retorno à instituição para continuidade de aprendizagens e conhecimentos.

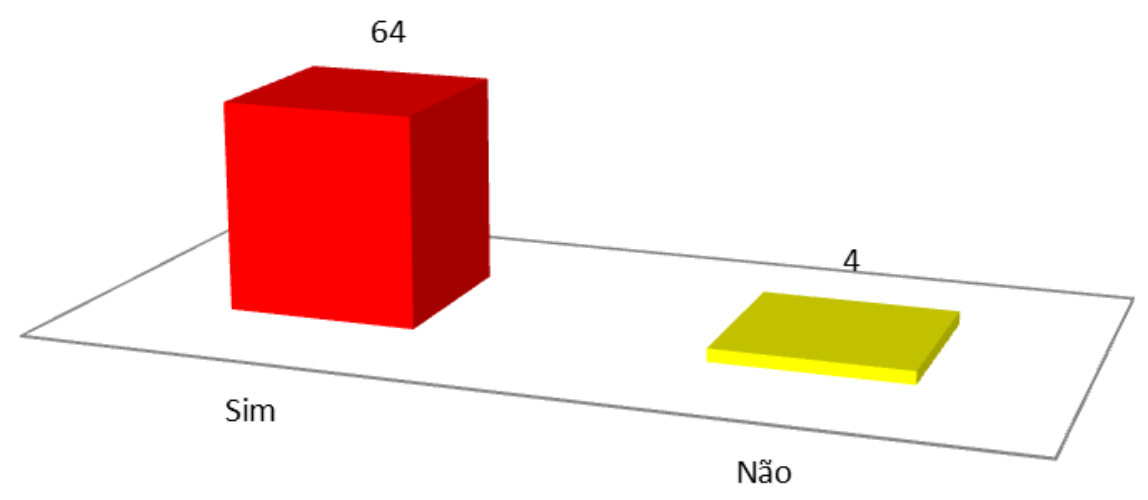

Gráfico 2: Distribuição de Egressos com relação ao retorno à Instituição para dar continuidade aos estudos. Fonte: Pesquisa Direta, 2014

A análise do gráfico supra mencionado nos permite constatar que um quantitativo de 64 egressos, correspondendo a $94 \%$ dos egressos, afirmaram que retornariam ao IFCE- Campus Maracanaú para dar prosseguimento aos seus estudos. Dentre as justificativas levantadas destacamos:

1) Retorno à Instituição para cursar uma graduação, no caso dos egressos que finalizaram o curso técnico, além da pós-graduação (nível de Especialização, Mestrado e Doutorado). É válido destacar que alguns Egressos já retornaram à instituição para cursar uma graduação na área de formação, estando atualmente na condição de estudante;

2) Retorno à IFCE pelo fato de ser uma Instituição que oferece uma infraestrutura e recursos humanos de ótima qualidade.

Os depoimentos dos egressos, de modo geral, apresentam uma visão bastante positiva no quesito à oferta de infraestrutura e recursos humanos pela instituição que propicia condições para uma formação profissional que atende as demandas profissionais, como podemos observar a seguir:

Além de haver ótimos professores, é uma instituição bastante reconhecida em âmbito nacional. Inclusive ingressarei no Instituto novamente para dar continuidade aos meus estudos no curso de Ciência da Computação em Julho de 2014, semestre 2014.1. (Egresso no 6 - Curso técnico em Informática);

\footnotetext{
${ }^{5}$ As pesquisas e discussões brasileiras sofreram influencias da Teoria do Capital Humano a partir dos anos de 1960 com enfoque na discussão sobre a correlação entre crescimento econômico e os níveis educacionais da sociedade capitalista. A centralidade das discussões girava em torno da responsabilidade da educação pelos baixos níveis de produtividade e de renda da população (SHIROMA 1997)
} 
O instituto possui ótimos profissionais que conseguem repassar de forma satisfatória seus conhecimentos, contribuindo diretamente para a formação de mão-de-obra qualificada. Com certeza, eu retornaria para uma futura especialização ou doutorado que venha a existir na minha área de estudo. (Egresso no 2 - Curso Superior em Manutenção Industrial).

Por outro lado, torna-se imprescindível considerar que diante da globalização da economia e crise do emprego nos dias atuais, alguns autores, como Ramos (2002), considera que há uma tendência de criação de novos códigos que adequem a educação às tendências produtivas. Isso quer dizer que há a exigência de preparar os jovens para o "mercado de trabalho", por meio da aquisição de competências, associadas às noções de empregabilidade e laborabilidade.

Apesar do levantamento de algumas problemáticas importantes em torno da qualificação adquirida pelo IFCE e sua relação com as demandas profissionais, alguns egressos informam que o conhecimento adquirido propiciou muito mais que a obtenção de emprego. Durante o processo de permanência no curso, o conhecimento adquirido possibilitou aprimoramento intelectual, mas também social, no sentido do egresso ter tido contato com colegas e professores que marcaram sua formação. Além disso, mencionaram a importância da obtenção de condições financeiras e infraestrutura para sua permanência e, consequentemente, êxito no processo formativo. Seguem depoimentos ilustrativos:

Sim, com certeza, adorei estudar no IFCE Campos Maracanaú, professores maravilhosos, aulas onde eu aprendi muita coisa, que vou levar por toda minha vida. Agora, é rumo à graduação. (Egresso no 5 - Curso técnico em meio ambiente);

Com toda certeza, o IFCE foi a minha segunda casa. A Instituição me forneceu total apoio para a realização de minhas atividades acadêmicas e para o meu crescimento pessoal e profissional. Espero a existência de cursos de mestrado e doutorado para que eu retorne a estudar nessa maravilhosa instituição (Egresso no 3 - Curso da Licenciatura em Química).

Mesmo sendo imprescindível o investimento numa infraestrutura que garanta a efetivação de uma formação para o trabalho, alguns egressos alertam para a necessidade urgente de fortalecer a relação do IFCE com as empresas do entorno, fortalecendo os vínculos entre a escola e a empresa, através dos estágios curriculares. Segue trecho de uma das falas dos sujeitos:

Sim, voltaria, pois os professores foram bastante competentes e a estrutura do Campus também estimulou a resposta positiva. Mas precisa ter um investimento na parte prática do curso, como construção de laboratórios específicos para cada disciplina essencial da automação, ex.: CLP, Supervisório, Eletro/Pneumática. É interessante também que se formem convênios com empresas da região, já que o curso é numa área que abrange bastante a indústria, contatos com fabricantes de equipamentos, pois todas essas práticas fazem um diferencial enorme quando o egresso consegue entrar na área. (Egresso no 5 - Curso técnico em Automação Industrial).

A necessidade de atualização e aquisição de conhecimentos diante da complexidade das demandas do mercado de trabalho citada pelos egressos, não deve estar desvinculada do contexto macrossocial, marcado por um sistema produtivo que visa à apropriação da mais valia, gerada pela força de trabalho, aliado à precarização das condições de trabalho e baixa remuneração frente à 
qualificação profissional adquirida. É o caso da situação dos egressos dos cursos técnicos em Automação Industrial que denunciam a busca do mercado de trabalho pelo técnico ao invés de contratação do tecnólogo. Essa situação acarreta em desestímulo do discente e do próprio egresso pelo curso de tecnólogo, acarretando na busca por outra graduação na área de Engenharia.

Apesar desse cenário, alguns egressos apontaram que as políticas no âmbito da Assistência Estudantil ${ }^{6}$, bem como os programas de bolsas de Iniciação Científica fizeram o diferencial, uma vez que garantiram a permanência do Egresso na instituição e, consequentemente, propiciou condições para o êxito no seu processo formativo. Segue alguns depoimentos ilustrativos:

Tive a oportunidade de cursar Graduação em uma faculdade federal, pouco tempo depois de ter concluído meu curso no IFCE e senti na pele a diferença. Os professores do instituto são muito companheiros, dedicados, presentes, respeitam seus alunos, as salas de aulas são climatizadas, bem iluminadas, não falta material didático, nem as mídias necessárias. Temos todo o apoio do setor pedagógico, social, enfermaria, secretaria e as coordenações dos cursos sem falar do lanche que é ótimo [...] ( Egresso no 9 - Curso Técnico em Informática.)

Porque é uma instituição comprometida com o aprendizado dos alunos e as oportunidades oferecidas de bolsas de pesquisa e auxílios para que os mesmos possam permanecer e concluir o curso são muito boas. (Egresso no 3 - Curso Superior em Licenciatura em Química).

Os depoimentos esclarecem a importância das políticas públicas de inclusão social em propiciar condições de igualdade social, bem como da escola na reprodução do saber, apesar deste apresentar um caráter excludente e seletivo. Na visão de Kuenzer (1991), o saber científico e tecnológico "de ponta" é produzido no interior das relações de produção, sendo desenvolvido e apropriado pelo capital. Cabe à escola, a sua distribuição e, muito embora, este tenha sido realizada segundo as necessidades do capital, a sua não democratização expressa pelo seu caráter seletivo e excludente não é uma disfunção, mas a sua própria forma de articulação com o capital.

Não obstante a autora supramencionada reconhecer os limites da formação profissional na escola, em termos de seu caráter de distribuição desigual do saber e da qualidade do saber reproduzido, a pesquisa deixou claro o valor do "certificado escolar", a medida que abre as portas para o desenvolvimento das funções intelectuais no mercado de trabalho e confere as habilidades, comportamentos e conhecimentos minimamente necessários para a aquisição de competência através do exercício profissional que lhe amplia o espaço de negociação.

\section{CONSIDERAÇÕES FINAIS}

Os principais resultados desta pesquisa nos permitiram observar, que a percepção dos egressos sobre a formação recebida na sua trajetória de aluno no IFCE, possibilitou uma

\footnotetext{
${ }^{6}$ A Assistência Estudantil no IFCE- Campus Maracanaú vem se consolidando como um conjunto de ações as quais visam ampliar as condições de permanência dos estudantes e apoiar a formação acadêmica do corpo discente. Uma dessas ações diz respeito à disponibilização de auxílio aos estudantes sob a forma de pecúnia, ou serviço ofertado na perspectiva de "viabilizar a igualdade de oportunidades, contribuir para a melhoria do desempenho acadêmico e agir, preventivamente, nas situações de retenção e evasão decorrentes da insuficiência de condições financeiras." (BRASIL, 2010).
} 
qualificação pautada nos conhecimentos formais, adquiridos através dos diplomas escolares e titulações. Contudo, esse conhecimento não se mostrou suficiente, dada a necessidade de atualização e aquisição de conhecimentos diante da complexidade das demandas do mercado de trabalho. Tais demandas exigiram também conhecimentos tácitos que nas palavras do egresso o preparou para "enfrentar situações fora do IFCE", ou seja, para as diversas situações que a realidade do ambiente de trabalho exige.

Ademais, a formação teórica adquirida vem relacionada com uma infraestrutura e recursos humanos de qualidade, garantindo resultados positivos, como a obtenção de emprego em menos de seis meses após a conclusão do curso na Instituição.

Foi possível observar, ainda, que os limites da formação profissional na escola são inegáveis, contudo o "certificado escolar" tem valor fundamental, uma vez que garantiu para a maioria dos egressos a qualificação profissional que os permitiu se inserir no mercado de trabalho.

Cabe destacar, que a percepção do egresso a respeito da sua formação no IFCE, Campus Maracanaú, delineados nesta pesquisa, não deve ser vista de forma absoluta, uma vez que a realidade é dinâmica e seu movimento se faz eivado de contradições. Mesmo diante das limitações que o estudo apresenta, este se fez importante por revelar aspectos da relação entre educação e trabalho na atualidade, na qual a escola como instituição formadora tem ocupado lugar central no processo de obtenção de conhecimentos, bem como por permitir entender que as habilidades e competências adquiridas nestas instituições não são apenas para o mero adestramento, do "saber fazer".

\section{REFERÊNCIAS}

1. BRASIL. Decreto no 7.234, de 19 de julho de 2010. Dispõe sobre o Programa Nacional de Assistência Estudantil - PNAES. Disponível em: < http://www.planalto.gov.br/ccivil_03/_ Ato20072010/2010/Decreto/D7234.htm>. Acesso em: 05.06.15.

2. CHINELLI, Filippina; DURÃO, Anna Violeta. Novos Conteúdos, nova forma e nova cultura do trabalho. O Mundo em Mudança: Virando o Milênio, Rio de Janeiro, v. 4, n. 6, p.99-105, jul. 1999. Semestral.

3. KERN, Horst. SCHUMANN, Michael. Das Ende der Arbeitsteilung? Rationalisierung in der industriellen Produktion. Munique: Verlag C. H. Beck, 1984.

4. KUENZER, Acácia. Educação e trabalho no Brasil: o estado da questão. Brasília: INEP, 1991.

5. PAIVA, Vanilda. La Ciudadania Negada. Políticas de Exclusión em la Educación y eltrabajo. Buenos Aires: Clacso, 2000.

6.

O mundo em mudança: deslocamento temático no final do século e a convivência com a incerteza. Contemporaneidade e Educação, ano VI, n ${ }^{\circ} 6$. Rio de Janeiro, Instituto de Estudos da Cultura e Educação Continuada, 1999.

7. RAMOS, Marise Nogueira. A Educação Profissional pela pedagogia das competências e a superfície dos documentos oficiais. Educação e Sociedade, Campinas, p.401-422, 2002. Disponível em < http://www.cedes.unicamp.br>. Acesso em abril de 2011.

8. SHIROMA, Eneida Oto; CAMPOS, Roselane Fátima. Qualificação e Reestruturação produtiva: um balanço das pesquisas em Educação. Educação e Sociedade, ano XVIII, № 61. Dezembro, 1997. 